\title{
The effect of incorporating fat into different components of a meal on gastric emptying and postprandial blood glucose and insulin responses
}

\author{
BY K. M. CUNNINGHAM AND N. W. READ \\ Sub-Department of Human Gastrointestinal Physiology and Nutrition, Floor K, \\ Royal Hallamshire Hospital, Sheffield S10 2JF
}

(Received 5 April 1988 - Accepted 14 October 1988)

\begin{abstract}
1. Three studies were carried out in each of six normal volunteers to investigate how lipid, when given at different stages during the course of a meal, affects gastric emptying and postprandial blood glucose and insulin concentrations.

2. The control meal consisted of $300 \mathrm{ml}$ beef consommé $(50 \mathrm{~kJ}, 12 \mathrm{kcal})$, followed $20 \mathrm{~min}$ later by $300 \mathrm{~g}$ mashed potato $(908 \mathrm{~kJ}, 217 \mathrm{kcal})$. In the two test meals, $60 \mathrm{~g}$ margarine were incorporated into either the soup or the mashed potato.

3. The addition of margarine to either component of the meal delayed gastric emptying of the mashed potato $(P<0.05)$, but the pattern varied according to the component to which the fat was added.

4. Incorporation of fat into the soup increased the lag phase $(P<0.05)$ but did not influence the slope of emptying of the mashed potato, while incorporation of fat into the mashed potato reduced the slope of emptying of the mashed potato $(P<0.05)$ but did not influence the lag phase.

5. Addition of fat to either component of the meal reduced postprandial blood glucose $(P<0.05)$ and insulin responses, but when the fat was incorporated in the soup, peak glucose and insulin responses were delayed as well $(P<0.05)$.

6. The results show that the effect of fat on gastric emptying and absorption of nutrients depends on when, in relation to the other components of the meal, the fat is consumed.
\end{abstract}

We have previously shown that infusion of lipid emulsions into the small intestine retards gastric emptying and reduces the insulinaemic and glycaemic responses to a meal of mashed potato (Welch et al. 1987). Incorporating the fat into the mashed potato meal had similar, though less pronounced effects (Welch et al. 1987). These differences in the results from the two experimental designs suggested that the effect of lipid on the gastric emptying and metabolic responses to a carbohydrate meal may vary according to whether the lipid is given independently of the carbohydrate or mixed with it. The present study has investigated the physiological relevance of this hypothesis by measuring the effect on gastric emptying and postprandial glycaemia and insulinaemia of incorporating lipid into a soup given before a meal of mashed potato or incorporating the same amount of lipid into the mashed potato.

\section{MATERIALS AND METHODS}

\section{Ethical considerations}

Three studies were carried out in each of six healthy male volunteers, aged between 20 and 28 years, all of whom had given their written informed consent. The experimental protocol was approved by the Ethical Sub-Committee of Sheffield Area Health Authority (Teaching).

\section{Meals}

The control meal consisted of $300 \mathrm{ml}$ beef consommé (Campbells, King's Lynn, Norfolk) containing $3 \mathrm{~g}$ fat, $1.2 \mathrm{~g}$ carbohydrate, $1.8 \mathrm{~g}$ protein $(50 \mathrm{~kJ}, 12 \mathrm{kcal})$, and $300 \mathrm{~g}$ mashed potato containing $68.3 \mathrm{~g}$ powdered mashed potato $(908 \mathrm{~kJ}, 217 \mathrm{kcal})$ plus $230 \mathrm{ml}$ water. A 
radioactive marker, consisting of $3.7 \mathrm{MBq}{ }^{99 \mathrm{~m}} \mathrm{Tc}$-tin colloid (Amersham International plc, Amersham, Bucks), was incorporated into the water that reconstituted the mashed potato. The radiation exposure to the gut was an effective dose equivalent of $0.1 \mathrm{mSv}$. In two studies, $60 \mathrm{~g}$ margarine $(1769 \mathrm{~kJ}, 422.8 \mathrm{kcal})$ (SUMA Sunflower Margarine, Halifax, West Yorks) was emulsified with either the soup or the mashed potato. In each case, the margarine replaced an equivalent amount of water keeping the volume of each meal constant. All three meals were palatable and were enjoyed by the subjects.

\section{Protocols}

The volunteers were instructed to avoid alcohol for a period of $48 \mathrm{~h}$ before each study, to have nothing to eat for at least $12 \mathrm{~h}$ and nothing to drink for at least $9 \mathrm{~h}$ before each study. Experiments were always conducted between 09.00 and 12.00 hours.

After a basal blood sample, the soup was served and was consumed in less than $5 \mathrm{~min}$. The subject then sat at an angle of $45^{\circ}$ under a gamma camera (Model 1201 Pho/Gamma, Nuclear-Chicago, Europea, NV, Amsterdam). Twenty min after the soup was served, the reconstituted mashed potato was spoon-fed and was eaten in less than 10 min. Gastric emptying and postprandial blood glucose and insulin levels were monitored for $150 \mathrm{~min}$. Repeated blood samples were obtained from an indwelling venous cannula placed in the forearm of the volunteer. Studies were separated by periods of at least 1 week and the order of the tests was randomized.

\section{Methods}

Gastric emptying. The rate of gastric emptying of the mashed potato was determined by monitoring the decline of radioactivity over the stomach using an anterior positioned gamma camera which was linked to a dedicated minicomputer. Images of the distribution of radioactivity in the abdomen were collected at intervals of $2 \mathrm{~min}$ for a total of $150 \mathrm{~min}$ and stored on magnetic disks. When the data were replayed a region of interest was drawn around the stomach and the number of radioactive counts in that region in every image was corrected for the decay of the isotope, and expressed as a percentage of the counts obtained in the total gastric region immediately after ingestion of the meal. These values were then used to construct profiles of gastric emptying. In each case, the profiles consisted of a lag period, during which the mashed potato did not empty from the stomach region and a period when the isotope appeared to empty from the stomach in a linear manner (the emptying phase). The duration of the lag phase and the slope of the emptying phase were measured. For the purpose of analysis, the lag phase was defined as the period of time between the ingestion of the mashed potato and the appearance of the isotope outside the gastric region of interest (Camillieri et al. 1985).

Plasma glucose and insulin. Blood samples were taken at intervals of $15 \mathrm{~min}$. These were centrifuged immediately, snap frozen and stored. Glucose was analysed using a glucose analyser (GM6, Analox, Hants). Insulin was determined by radioimmunoassay.

\section{Statistical methods}

Statistical significance of differences between the responses to each meal was estimated using analysis of variance. A one-tailed paired $t$ test was performed to establish the level of significance between test meals and test meals and their controls.

\section{RESULTS}

\section{Gastric emptying}

Incorporating the fat into either component of the meal slowed gastric emptying of the mashed potato. Although the half times were prolonged to a similar extent $(P<0.05)$ 

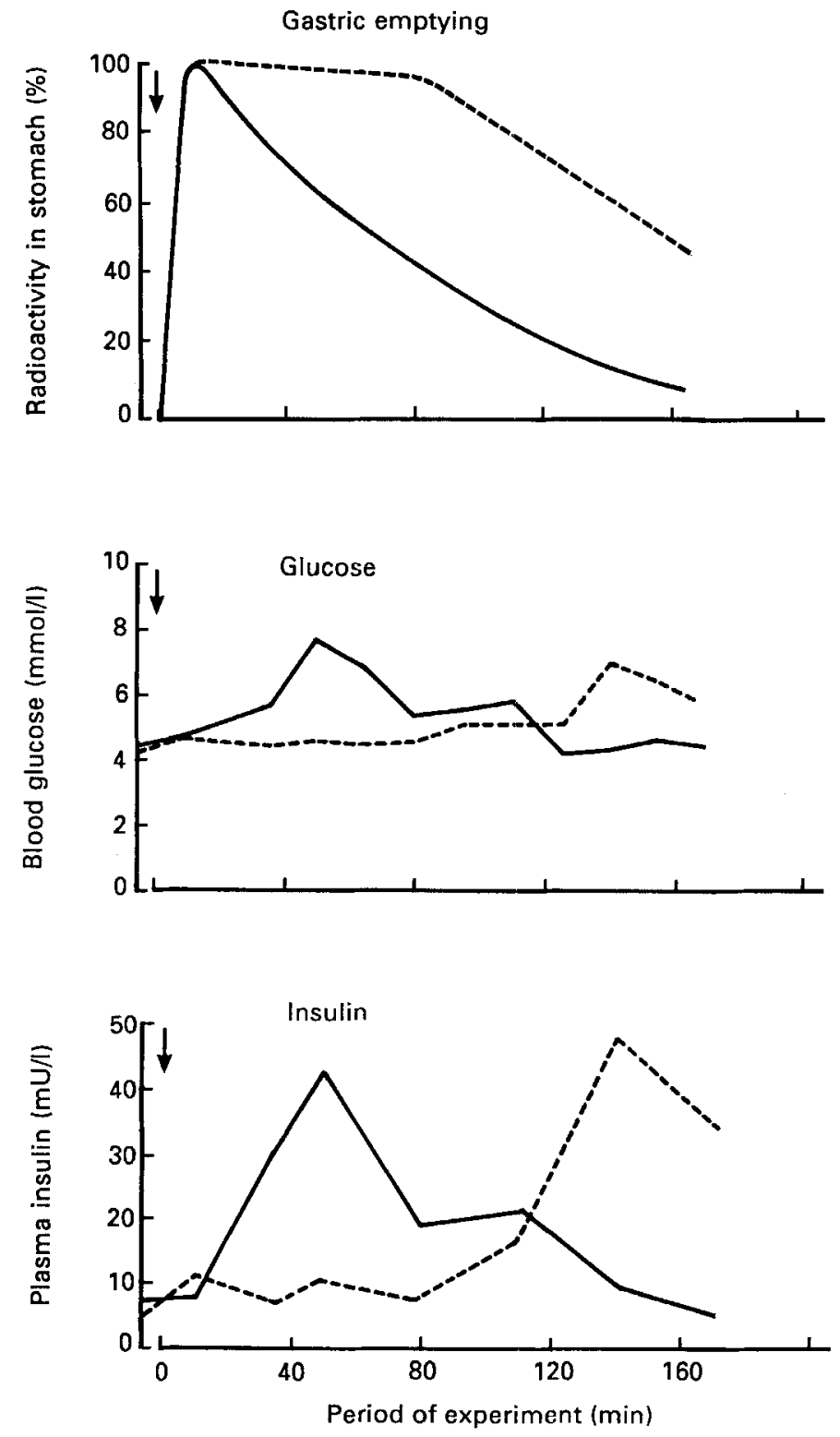

Fig. 1. A typical example of the effect of incorporating fat into a soup, followed 20 min later by $300 \mathrm{~g}$ mashed potato, on gastric emptying of the mashed potato and postprandial blood glucose and insulin levels in adult male subjects. $\downarrow$, The start of mashed potato consumption. For details of meal components, see pp. 285-286. (-), Control meal; (---), high-fat soup.

(Table 1), the effects on the gastric emptying profiles were different (Fig. 1). Incorporating the fat into the soup prolonged the lag phase $(P<0.05)$ without significantly affecting the slope of the emptying phase (Table 1). In contrast, incorporating fat into the mashed potato reduced the slope of the emptying phase $(P<0.05)$ without affecting the length of the lag phase (Table 1). 
Table 1. The effect of fat in different components of a meal $\dagger$ on gastric emptying in adult male subjects

(Mean values with their standard errors for six subjects)

\begin{tabular}{|c|c|c|c|c|c|c|}
\hline & \multicolumn{2}{|c|}{ Control } & \multicolumn{2}{|c|}{ Soup and fat } & \multicolumn{2}{|c|}{ Potato and fat } \\
\hline & Mean & SEM & Mean & SEM & Mean & SEM \\
\hline Half emptying time (min) & 67 & 7 & $114^{*}$ & 11 & $102^{*}$ & 9 \\
\hline Lag period (min) & 2 & 1 & $31.7^{*}$ & 7 & $4 * *$ & 1 \\
\hline Gastric-emptying slope $(\% / \mathrm{min})$ & $0 \cdot 9$ & $0 \cdot 1$ & 0.8 & $0 \cdot 1$ & $0 \cdot 6^{*}$ & $0 \cdot 1$ \\
\hline
\end{tabular}

* Mean values were significantly different from those values obtained with the fat-free meal $(P<0.05)$.

** Mean value was significantly different from that obtained with the high-fat soup meal $(P<0-05)$.

$\uparrow$ For details of meal components, see pp. 285-286.

Table 2. The effect of fat when incorporated into different components of a meal on glycaemic and insulinaemic responses to ingestion of a carbohydrate meal $\dagger$ by adult male subjects

(Mean values with their standard errors for six subjects)

\begin{tabular}{|c|c|c|c|c|c|c|}
\hline & \multicolumn{2}{|c|}{ Control } & \multicolumn{2}{|c|}{ Soup and fat } & \multicolumn{2}{|c|}{ Potato and fat } \\
\hline & Mean & SEM & Mean & SEM & Mean & SEM \\
\hline \multicolumn{7}{|l|}{ Glucose responses } \\
\hline Peak glucose value $(\mathrm{mmol} \cdot \mathrm{l})$ & $9 \cdot 1$ & 0.5 & $7 \cdot 5^{*}$ & 0.4 & $6 \cdot 6^{*}$ & $0 \cdot 4$ \\
\hline Time to peak (min) & 57 & 3 & $115^{*}$ & 14 & $50 * *$ & 10 \\
\hline $\begin{array}{l}\text { Area under the curve } \\
(\mathrm{mmol} \cdot \mathrm{l} \text { per } \mathrm{min})\end{array}$ & 2248 & $31 \cdot 5$ & $1398^{*}$ & 198 & $1024^{*}$ & 205 \\
\hline \multicolumn{7}{|l|}{ Insulin responses } \\
\hline Peak insulin value $(\mathrm{mU} \cdot \mathrm{l})$ & 53.5 & 4.7 & 34.8 & $6 \cdot 2$ & $32 \cdot 2$ & $7 \cdot 3$ \\
\hline Time to peak (min) & 75 & $9 \cdot 2$ & 110 & $15 \cdot 5$ & $60^{* *}$ & $6 \cdot 3$ \\
\hline $\begin{array}{l}\text { Area under the curve } \\
(\mathrm{mmol} \cdot \mathrm{l} \text { per } \mathrm{min})\end{array}$ & 3004 & 292 & $1961^{*}$ & 409 & $1356^{*}$ & 217 \\
\hline
\end{tabular}

* Mean values were significantly different from those obtained with the fat-free meal $(P<0.05)$.

** Mean values were significantly different from those obtained with the high-fat soup meal $(P<0.05)$.

$\dagger$ For details of meal components, see pp. 285-286.

\section{Plasma glucose}

Incorporating fat into either the mashed potato or, to a lesser extent, the soup, reduced the peak postprandial glucose levels and reduced the areas under the glucose profiles $(P<0.05)$ (Table 2). There was, however, a difference in the shape of the glucose profiles after the two types of high-fat meal (Figs. 1 and 2). Incorporating the lipid into the soup delayed the occurrence of the peak glucose level $(P<0.05)$ (Table 2$)$ whilst no significant delay was seen when fat was incorporated in the mashed potato.

\section{Plasma insulin levels}

Incorporating lipid into either the mashed potato or to a lesser extent the soup reduced the areas under the insulin profiles $(P<0.05)$ (Table 2, Fig. 1). Moreover, the insulin peak occurred later when lipid was added to the soup than when it was added to the mashed potato $(P<0.05)$ (Table 2$)$. 

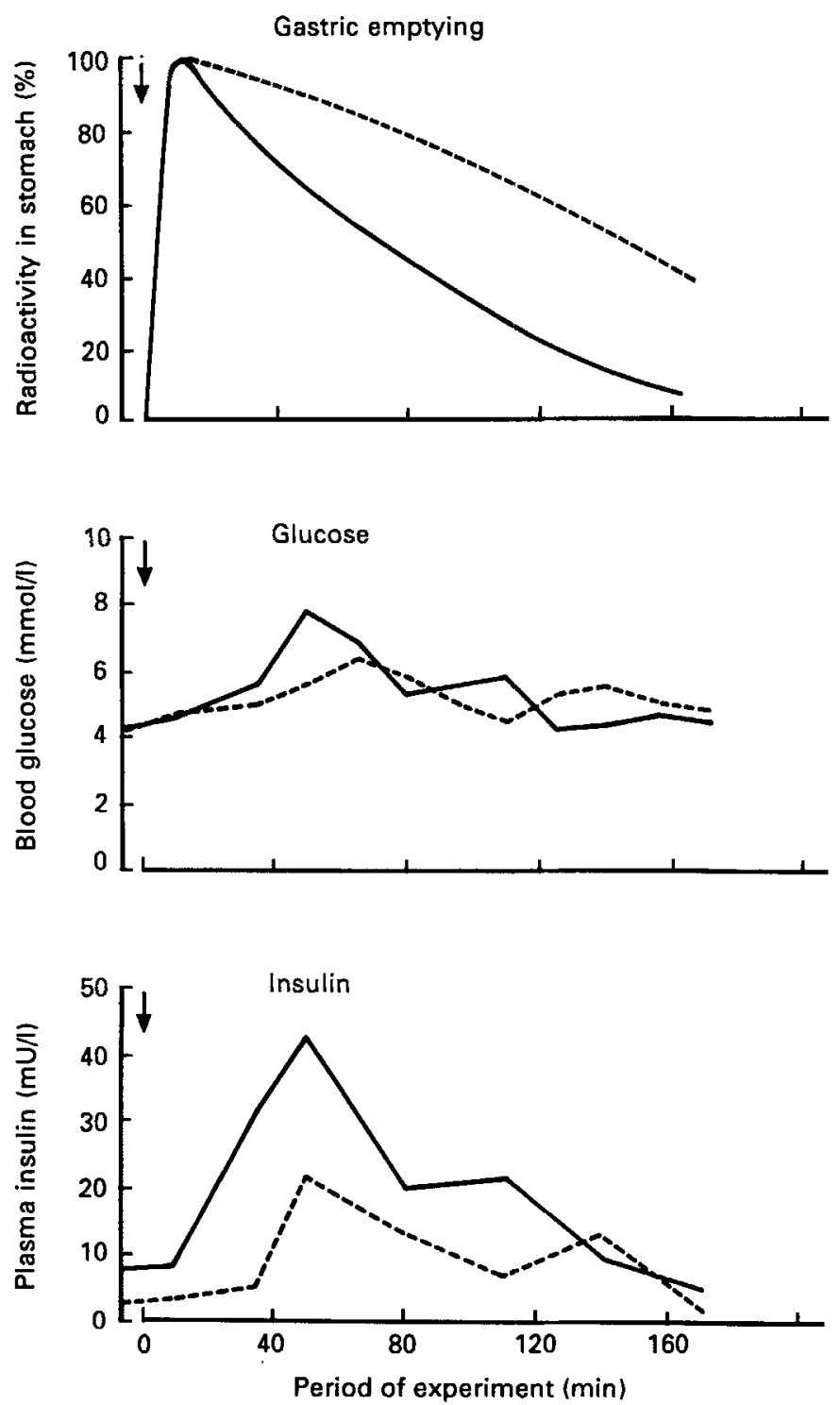

Fig. 2. A typical example of the effect of incorporating fat into $300 \mathrm{mg}$ mashed potato, served $20 \mathrm{~min}$ after a low-fat soup, on gastric emptying of the mashed potato and postprandial blood glucose and plasma insulin levels in adult male subjects. $\downarrow$, The start of mashed potato consumption. For details of meal components, see pp. 285-286. ( - ), Control meal; (---), high-fat soup.

\section{DISCUSSION}

The results of the present study show that incorporating lipid into different components of a meal, consisting of soup and mashed potato, has markedly different effects on the profiles of gastric emptying of a marker, incorporated in mashed potato, and postprandial plasma concentrations of glucose and insulin.

Incorporating $60 \mathrm{~g}$ fat into a soup served $20 \mathrm{~min}$ before a mashed-potato meal delayed 
the onset of emptying of the marker in the mashed potato by about $0.5 \mathrm{~h}$. This effect is probably related to the interaction of the lipid in the soup with duodenal lipid receptors (Cortot et al. 1982) since previous studies have shown clearly that duodenal infusion of lipid delays the emptying of mashed potato from the stomach (Welch et al. 1987). When the fat was incorporated into the mashed potato, the marker ingested with the mashed potato started to empty almost immediately but the slope of emptying was reduced.

The difference in profiles of gastric emptying is probably related to the different patterns of delivery of the lipid to the duodenum. We have previously shown that the solid component of a meal will not empty from the stomach until the majority of liquid has emptied (Houghton et al. 1988), and that the incorporation of hyperosmotic glucose into the liquid phase of a mixed meal acts on small intestinal receptors to slow the emptying of the liquid phase and delays the onset of emptying of the solid material without affecting its rate of emptying (Houghton et al. 1988). Incorporation of lipid also slows the emptying of the liquid phase (Cortot et al. 1982) by interacting with small intestinal receptors, and this delays the onset of emptying of a marker in the mashed potato. Thus, although the radioactive marker is incorporated into the liquid reconstituting the mashed potato, it appears to behave as a solid phase marker and its emptying is delayed by the lipid soup although the slope is unaltered. In contrast, the slow emptying of the mashed potato marker without any delay in the onset of emptying is compatible with the close association of lipid with the potato, since the lipid can only interact with duodenal receptors and slow emptying as the mashed potato is leaving the stomach.

It seems likely that these differences in gastric emptying profiles are responsible for the differences in plasma glucose levels. Plasma glucose responses were lower after both fatty meals compared with the control meal. These reductions in plasma glucose were not caused by enhanced insulin secretion. Insulin responses to the fatty meals were in fact lower than the control meals and tended to follow a pattern that was similar to the glucose responses. The greater tendency to lower glucose and insulin levels with the high-fat potato rather than the high-fat soup reflects a slower rate of solid emptying. The delay in the appearance of glucose and insulin peaks when lipid was incorporated into the soup was associated with a delayed onset of emptying of the mashed potato.

The results of the present study suggest that if lipid is to be used in modifying the nutrient response to a meal, then different effects can be achieved by incorporating the lipid into different components of the meal.

\section{REFERENCES}

Camillieri, M., Malagelada, J.-R., Brown, M. L., Becker, G. \& Zinsmeister, A. R. (1985). Relation between antral motility and gastric emptying of solids and liquids in humans. American Journal of Physiology 259, G580-G585.

Cortot, A., Phillips, S. F. \& Malagelada, J.-R. (1982). Parallel gastric emptying of non-hydrolyzable fat and water after a solid-liquid meal in humans. Gastroenterology 82, 877-881.

Houghton, L. A., Read, N. W., Heddle, R. A., Horowitz, M., Collins, P. J. \& Dent, J. (1988). Relationship of the motor activity of the antrum, pylorus and duodenum to gastric emptying of a solid liquid mixed meal. Gastroenterology 9, 1285-1291.

Welch, I. McL., Bruce, C., Hill, S. E. \& Read, N. W. (1987). Duodenal and ileal lipid suppresses postprandial blood glucose and insulin responses in man: possible implications for the dietary management of diabetes mellitus. Clinical Science and Metabolic Medicine 72, 209-216. 